Enoch Brandão de Souza MEIRA JR ${ }^{1}$

Huber RIZZO'

Fernando José BENESI ${ }^{1}$

Lilian GREGORY ${ }^{1}$

Correspondência para:

Lilian Gregory, Av. Prof. Orlando Marques de Paiva 87, Cidade Universitária, São Paulo, 05508-000; Igregory@usp.br

Recebido para publicação: 14/10/2008 Aprovado para publicação: 24/09/2009

\title{
Influência dos fatores sexuais e etários sobre a proteína total, fração albumina e atividade sérica de aspartato-aminotransferase e gama-glutamiltransferase de ovinos da raça Santa Inês
}

1 - Faculdade de Medicina Veterinária e Zootecnia da Universidade de São Paulo, São Paulo-SP

\section{Resumo}

O presente estudo estabelece valores de referência dos teores séricos de proteínas totais, albumina, AST e GGT em ovinos da raça santa Inês e avalia a interferência de fatores sexuais e etários sobre estas variáveis. Foram colhidas amostras de sangue de 161 ovelhas. O resultado encontrado para os valores padrões séricos foram $5,86+$ $0,96 \mathrm{~g} / \mathrm{dL}$ para proteínas totais, 2,33+0,43 $\mathrm{g} / \mathrm{dL}$ para albumina, 63,25+27,52 U/L para AST e 28,45+14,53 U/L para GGT. A análise dos resultados permite afirmar que os valores referentes à concentração sérica de albumina e à atividade sérica de AST sofrem influência de fatores sexuais e etários, e os valores referentes à atividade sérica de GGT sofrem influência somente de fatores etários. Não foram encontradas influências dos fatores sexuais e etários para os outros parâmetros estudados.

\section{Introdução}

Estudos para determinação ou avaliação da variabilidade dos valores de referência e parâmetros fisiológicos de animais domésticos sadios são básicos para o clínico veterinário analisar as alterações decorrentes de diversas doenças. Como existem limitações do exame físico em detectar alterações da função de certos órgãos ou sistemas, as provas bioquímicas realizadas no soro sangüíneo dos animais domésticos representam um excelente subsídio ao diagnóstico clínico de inúmeras enfermidades, destacando-se aquelas com sede ou repercussões sobre o fígado e que, freqüentemente, alteram as funções ou estruturas deste órgão. Por estas razões, usualmente na rotina clínica, os referidos exames são reunidos em grupos, provas referidas como avaliadoras da função hepática, considerando os seguintes exames bioquímicos do soro sangüíneo: determinação do proteinograma; determinação das bilirrubinas e provas que avaliam a integridade do sistema hepatobiliar como a avaliação da atividade de Aspartatoaminotransferase (AST) e da atividade de Gama-glutamiltransferase (GGT). ${ }^{1}$

$\mathrm{O}$ estudo do proteinograma sérico dos animais domésticos é de fundamental importância como subsídio ao diagnóstico clínico de enfermidades hepáticas ou que interferem com a função deste órgão. Todavia, para a sua adequada aplicabilidade em Patologia Clínica Veterinária, é necessário estabelecerem-se valores padrões de referência. A fração albumina, uma das proteínas séricas de menor peso molecular, ocorre em maior quantidade no soro sangüíneo sendo responsável pelo carreamento de diversos íons e ácidos graxos no sangue, além de ter função de regularizar a pressão oncótica. ${ }^{2} \mathrm{~A}$ avaliação da atividade das enzimas hepáticas constitui uma das melhores provas para verificar a integridade do fígado. ${ }^{3}$ A GGT possui maior atividade no córtex renal, medula renal, pâncreas, glândula mamária e fígado, sofrendo variações conseqüentes ao desenvolvimento 
etário, e significativas em doenças hepatobiliares de ruminantes. ${ }^{4}$ Inúmeros são os fatores de variabilidade descritos como possíveis causadores de significativas alterações nos resultados das provas bioquímicas, realizadas em amostras de soro sangüíneo de ovinos. Alguns desses fatores poderiam ser considerados como intrínsecos, portanto, pertinentes às condições inerentes do indivíduo tais como espécie, raça, idade, sexo; outros fatores poderiam ser referidos como extrínsecos, relacionando-se à adaptação dos animais ao meio ambiente ou ao sistema de criação, como as condições ambientais e climáticas, manejo de criação e alimentação ou doenças endêmicas. Além do mais não se poderia deixar de mencionar as variações causadas pela metodologia utilizada para as determinações, pela técnica de colheita ou da conservação das amostras. ${ }^{5}$

O tema vem despertando o interesse de diversos pesquisadores, de modo que estes estabeleceram padrões de referência para ovinos de diferentes raças, regiões e manejos. Young et al. ${ }^{6}$ determinaram a atividade sérica de AST em ovinos criados nos EUA e avaliaram a influência de diferentes condições de manejo como animais criados a pasto $(96,27 \pm 4,21 \mathrm{U} / \mathrm{L})$ e em confinamento $(70,64 \pm 10,1 \mathrm{U} / \mathrm{L})$. Weaver ${ }^{7}$ determinou as concentrações séricas de proteína total $(8,5 \pm 0,8 \mathrm{~g} / \mathrm{dL})$ e albumina $(3,0 \pm 0,6 \mathrm{~g} / \mathrm{dL})$ e a atividade sérica de AST $(125 \pm 48 \mathrm{U} / \mathrm{L})$ e GGT $(15 \pm 9 \mathrm{U} / \mathrm{L})$, avaliando a influência dos fatores sexuais e etários. Márquez et al. ${ }^{8}$ padronizaram valores para a determinação da atividade sérica de GGT e encontraram valores em torno de $33,5 \pm 4,3$ U/L. Healy e Falk ${ }^{9}$ determinaram as concentrações séricas de proteína total e da fração albumina e a atividade sérica de AST de animais criados na Austrália, avaliando a influência da raça, das condições de manejo, da idade, do sexo e do estado fisiológico, os autores encontraram que condições de manejo e ambiente influenciavam muito pouco nos parâmetros estudados, enquanto a proteína total, a albumina e AST sofriam influência do fator etário. Foram encontrados maiores valores nos animais mais velhos. Gardner ${ }^{10}$ determinou valores padrões de referência para a concentração sérica de proteína total, albumina e para a atividade sérica de AST avaliando a influência da idade nestes valores. $\mathrm{O}$ autor concluiu que os animais mais velhos possuíam menores valores de proteína total que os animais mais jovens, em conseqüência da ingestão por estes de colostro. Ford et al. ${ }^{11}$ estabeleceram valores normais para a atividade sérica de AST e GGT e avaliaram o efeito de lesões renais e hepáticas sobre estes. Concluíram que estas enzimas podem ser utilizadas como parâmetros para avaliação destes órgãos sendo que a atividade sérica da GGT foi maior em casos de colestase. Boss, Gerber e Tschudi ${ }^{12}$ determinaram a influência exercida por fatores raciais, etários e sexuais de animais criados na Suíça. Os autores encontraram maiores valores de proteína em animais mais velhos assim como houve influência do fator raça para este parâmetro. Não houve diferença entre os gêneros para os parâmetros estudados. Gohary e Bickhardt ${ }^{13}$ avaliaram a influência do estresse da colheita sobre o proteinograma e sobre a atividade sérica de AST $(31,7 \pm 7,5 \mathrm{U} / \mathrm{L})$ e GGT $(32,4 \pm 8,7 \mathrm{U} / \mathrm{L})$ em animais de diferentes raças, idades e sexo e verificaram um aumento dos parâmetros após a primeira colheita para AST $(33,0 \pm 7,8 \mathrm{U} / \mathrm{L})$ e GGT $(34,0 \pm 10,5 \mathrm{U} / \mathrm{L})$, provando o efeito de estresse sobre os parâmetros referidos. Sykes, Coop e Robinson ${ }^{14}$ avaliaram a importância da determinação da atividade sérica de AST e GGT para o diagnóstico da fasciolose e ressaltaram a importância da atividade sérica de GGT para determinar danos em ductos biliares. Ramos et al. ${ }^{15}$ determinaram os valores padrões de referência para as concentrações séricas de proteína total $(6,7$ $\pm 0,68 \mathrm{~g} / \mathrm{dL})$, atividade sérica de AST (140,1 \pm 3,46 U/L) e GGT $(64,5 \pm 14,1 \mathrm{U} / \mathrm{l}) \mathrm{em}$ animais da raça Aragonesa criados na Espanha. Nesse estudo ainda avaliaram a influência do fator etário e determinaram maiores valores de proteína total e maiores atividades de AST e GGT em animais mais 
jovens e também maiores teores de GGT em animais em lactação. Baumgartner e Pernthaner ${ }^{16}$ avaliaram a influência $d a$ lactação que determinou maiores atividades séricas de GGT e AST em relação aos demais estados fisiológicos. Avaliaram também a influência da idade, do sexo, da raça e da estação do ano sobre as concentrações séricas e não encontraram significâncias atribuíveis a estes fatores. As médias dos valores de proteína total foram $(5,3-8,0 \mathrm{~g} / \mathrm{dL})$, da fração albumina foram $(2,1-3,8 \mathrm{~g} / \mathrm{dL})$ e das atividades séricas de AST $(18 \mathrm{U} / \mathrm{L})$ e GGT $(26 \mathrm{U} / \mathrm{L})$ em animais criados na Áustria. Dias et al. ${ }^{17}$ determinaram padrões de referência para animais da raça Churra da Terra Quente criados em Portugal. Encontraram para a atividade sérica de AST, um resultado de $165,0 \pm 48,3 \mathrm{U} / \mathrm{L}$, para a atividade sérica de GGT $48,0 \pm 18.7 \mathrm{U} / \mathrm{L}$ e para proteínas totais 7,5 $\pm 0,6 \mathrm{~g} / \mathrm{dL}$. Ribeiro et al. ${ }^{18}$, Brito et al. ${ }^{19}$ e Balikci, Yildiz e Gürdogan ${ }^{20}$ avaliaram a influência do estado fisiológico na determinação dos valores referentes às concentrações séricas de proteína total e albumina. Ribeiro et al. ${ }^{18}$ concluíram que com o avançar da gestação os animais apresentavam valores de proteína total e albumina menores do que animais no início da gestação (proteína total 7,28 para 7,21g/ dL; albumina 3,1 para 2,4 g/dL). Brito et al. ${ }^{19}$ e Balikci, Yildiz e Gürdogan ${ }^{20}$ não encontraram variação significativa entre os diferentes estados fisiológicos.

Neste estudo objetivou-se determinar valores padrões de referência para as concentrações séricas de proteína total e de sua fração albumina e as atividades séricas de AST e GGT em ovinos da raça Santa Inês, criados na região de Piedade no estado de São Paulo, em regime de semiconfinamento e avaliar a influência exercida pelos fatores etário e sexual sobre estes parâmetros.

\section{Material e Método}

Foram utilizados 161 ovinos da raça Santa Inês, criados em propriedades na região de Piedade, no Estado de São Paulo. Os animais utilizados foram escolhidos com base em avaliação clínica das condições de saúde, independente de estarem gestantes ou em lactação. Os não considerados hígidos foram excluídos do estudo. Foram constituídos três grupos experimentais, um envolvia todos os animais utilizados independentes de sexo ou idade, outro dividia os machos e fêmeas independente da idade e o último compreendia os animais de idade conhecida divididos conforme estratificação etária, sem descriminação por gênero, realizada com a separação dos ovinos em três subgrupos etários. O primeiro compreendeu os animais com até 6 meses de idade, o segundo compreendeu os animais que estavam entre sete e 18 meses de idade e o terceiro compreendeu os animais com idades superiores a 18 meses. Após a seleção, colheram-se amostras de sangue através da punção da veia jugular externa, sem o garroteamento excessivo do vaso, utilizandose tubos de vidro siliconizados com e sem anticoagulante e com vácuo suficiente para aspirar $10 \mathrm{~mL}$ de sangue, as amostras dos tubos com anticoagulante foram destinadas a obtenção do hemograma como parte da avaliação clínica dos animais, as amostras dos tubos sem anticoagulante foram submetidas à centrifugação para posterior obtenção do soro que foi armazenado $\mathrm{a}-20^{\circ} \mathrm{C}$ até o momento da análise. A atividade enzimática da aspartatoaminotransferase sérica foi determinada em analisador bioquímico automático marca Bayer modelo RA-100, utilizando-se kit comercial da Merck (número de artigo 124.362).

A atividade enzimática da gamaglutamiltransferase sérica foi determinada segundo metodologia cinética otimizada, em analisador bioquímico automático marca Bayer modelo RA-100, utilizando-se kit comercial da Merck (número de artigo 125.938). A determinação dos teores séricos de proteínas totais foi feita através do método de biureto, de acordo com a técnica preconizada ${ }^{21} \mathrm{e}$ modificada $^{22}$. A determinação dos teores séricos de albumina foi realizada por meio do método do verde de bromocresol, de acordo com a técnica preconizada por Doumas e Bigges $^{23}$ modificada. A fim de calcular os 
valores da média aritmética, do desvio-padrão e do coeficiente de variação dos resultados obtidos para os componentes bioquímicos sangüíneos avaliados nesta pesquisa, assim como para realizar os testes estatísticos, comparando as médias obtidas nos vários grupos experimentais, foi utilizado o programa Graphpad Instat versão três. Em princípio, os resultados foram submetidos à análise de variância, sendo o contraste entre médias analisado pelo Teste $\mathrm{t}$ em amostras paramétricas e teste de Mann Whitnney em amostras não paramétricas, com níveis de significância igual a $5 \%(\mathrm{p}=0,05)^{24}$.

\section{Resultados}

Os resultados obtidos na determinação de proteínas totais séricas, na determinação da albumina sérica, na avaliação das atividades das enzimas Aspartato-aminotransferase (AST) e
Gama-glutamiltransferase (GGT) do sangue circulante de 161 ovinos sadios, da raça Santa Inês, criados na região de Piedade, no Estado de São Paulo e seus respectivos desvios-padrão foram distribuídos em três tabelas, enumeradas de 1 a 3 segundo os valores médios gerais e de acordo com o sexo e faixa etária, conforme foi proposto no presente trabalho.

Observou-se que não houve diferença estatisticamente significante para os valores de proteínas séricas totais $(\mathrm{P}=0,1376)$, da fração albumina $(\mathrm{P}=0,1960)$ e os referentes à atividade sérica de $\mathrm{GGT}(\mathrm{P}=0,4484)$ entre os sexos. Observou-se que existe diferença entre as médias dos valores referentes à atividade sérica de AST $(\mathrm{P}<0,0001)$ entre os sexos. As fêmeas apresentaram valores maiores que os dos machos.

Não houve diferenças significantes dos valores referentes à concentração sérica de proteínas totais entre o grupo 1 e o grupo

Tabela 1 - Valores das médias e desvios-padrões de proteína total, de albumina sérica e das atividades séricas das enzimas AST e GGT de ovinos sadios da raça Santa Inês, criados na região de Piedade, no Estado de São Paulo - 2008

\begin{tabular}{ccc}
\hline Parâmetros & \multicolumn{3}{c}{ Ovinos da raça Santa Inês } \\
& $\bar{n}=161$ & s \\
\cline { 2 - 3 } & 58,60 & $\pm 9,60$ \\
\hline Proténas Séricas Totais $(\mathrm{g} / \mathrm{L})$ & & $\pm 4,30$ \\
\hline Albumina Sérica (g/L) & 23,3 & $\pm 27,52$ \\
\hline AST (U/L) & 63,25 & $\pm 14,53$ \\
\hline GGT (U/L) & & \\
\hline
\end{tabular}

$(\overline{\bar{x}})$ refemte a média e (s) referente ao desvio padrão

Tabela 2 - Valores das médias e desvios-padrões de proteína total, de albumina sérica e das atividades séricas das enzimas AST e GGT de ovinos sadios da raça Santa Inês, segundo o sexo, criados na região de Piedade, no Estado de São Paulo - 2008

\begin{tabular}{|c|c|c|c|c|}
\hline \multirow[t]{2}{*}{ Parâmetros } & \multicolumn{2}{|c|}{$\begin{array}{c}\text { Machos } \\
\mathbf{n}=35\end{array}$} & \multicolumn{2}{|c|}{$\begin{array}{l}\text { Fêmeas } \\
\mathbf{n}=126\end{array}$} \\
\hline & $\bar{x}$ & $\mathrm{~s}$ & $\bar{x}$ & $\mathrm{~s}$ \\
\hline $\begin{array}{c}\text { Proteínas Séricas } \\
\text { Totais }(\mathrm{g} / \mathrm{L})\end{array}$ & 56,40 a & $\pm 10,90$ & $59,20 \mathrm{a}$ & $\pm 9,10$ \\
\hline $\begin{array}{c}\text { Albumina Sérica } \\
(\mathrm{g} / \mathrm{L})\end{array}$ & $24,20 \mathrm{a}$ & $\pm 4,60$ & $23,10 a$ & $\pm 4,30$ \\
\hline AST $(\mathrm{U} / \mathrm{L})$ & $57,20 \mathrm{~b}$ & $\pm 20,99$ & 64,93 a & $\pm 28,92$ \\
\hline GGT (U/L) & $30,16 \mathrm{a}$ & $\pm 16,92$ & $27,97 a$ & $\pm 13,83$ \\
\hline
\end{tabular}


Tabela 3 - Valores das médias e desvios-padrões de proteína total, de albumina sérica e das atividades séricas das enzimas AST e GGT de ovinos sadios da raça Santa Inês, segundo as faixas etárias, criados na região de Piedade, no Estado de São Paulo - 2008

\begin{tabular}{ccccccc}
\hline \multirow{2}{*}{ Parâmetros } & \multicolumn{2}{c}{ Grupo 1 } & \multicolumn{2}{c}{ Grupo 2 } & \multicolumn{2}{c}{ Grupo 3 } \\
\cline { 2 - 7 } & \multicolumn{2}{c}{$\begin{array}{c}\leq \text { que } 6 \text { meses de idade } \\
\mathrm{n}=25\end{array}$} & $\begin{array}{r}7 \text { a } 18 \text { meses de idade } \\
\mathbf{n}=13\end{array}$ & $\begin{array}{c}\text { > que 18 meses de idade } \\
\mathrm{n}=35\end{array}$ \\
\cline { 2 - 7 } & $\bar{x}$ & $\mathrm{~s}$ & $\bar{x}$ & $\mathrm{~s}$ & $\bar{x}$ & $\mathrm{~s}$ \\
\hline $\begin{array}{c}\text { Proteínas } \\
\text { Séricas Totais } \\
\text { (g/L) }\end{array}$ & $58,00 \mathrm{a}, \mathrm{b}$ & $\pm 12,70$ & $50,80 \mathrm{~b}$ & $\pm 6,80$ & $58,60 \mathrm{a}$ & $\pm 8,70$ \\
\hline $\begin{array}{c}\text { Albumina } \\
\text { Sérica (g/L) }\end{array}$ & $24,00 \mathrm{a}$ & $\pm 4,50$ & $19,60 \mathrm{~b}$ & $\pm 4,60$ & $21,80 \mathrm{~b}$ & $\pm 4,70$ \\
\hline AST (U/L) & $49,90 \mathrm{~b}$ & $\pm 12,86$ & $59,47 \mathrm{a}, \mathrm{b}$ & $\pm 16,15$ & $61,36 \mathrm{a}$ & $\pm 13,92$ \\
& & & & & & \\
\hline GGT (U/L) & $33,43 \mathrm{a}$ & $\pm 11,76$ & $31,23 \mathrm{a}$ & $\pm 8,67$ & $27,80 \mathrm{a}$ & $\pm 11,26$
\end{tabular}

Letras diferentes ao hdo dos valores dasmédias indicam diferença estatisticamente significante entre as faixas etánas (P $\leq 0,05)$. $(\bar{X})$ refemte a média e (s) referente ao desvio padrão

$2(\mathrm{P}=0,0666)$ e entre o primeiro e o terceiro grupos etários $(\mathrm{P}=0,8631)$, foi observada diferença significante entre os grupos 2 e 3 $(\mathrm{P}=0,055)$. Quanto às médias referentes às concentrações séricas de albumina nota-se diferenças significativas entre o grupo etário 1 e o grupo etário $2(\mathrm{P}=0,0127)$ e entre o grupo etário 1 e o grupo etário $3(\mathrm{P}=0,0155)$. Nos valores referentes às médias da atividade sérica de AST observa-se que os animais do grupo etário 1 apresentaram diferença significante com relação aos animais do grupo $3(\mathrm{P}=0,0019)$. Nota-se também que estes valores aumentaram gradativamente com o aumento da faixa etária. Os valores referentes às médias da atividade sérica de GGT não apresentaram diferença entre as médias dos grupos.

\section{Discussão}

Os valores de proteínas totais séricas encontrados no presente estudo mantiveramse em geral semelhantes aos valores de referência estabelecidos para a espécie. . $, 9,10,12,13,15,16,17,18,19,20$ Nos animais lactentes encontram-se valores mais altos de proteínas totais em função da ingestão recente de colostro, se consumido no momento apropriado pelos cordeiros. ${ }^{9,10,15}$
Não foram encontrados nesta pesquisa valores de proteínas maiores no primeiro grupo, pois além de lactentes este compreendia animais até 6 meses de idade. Os valores correspondentes às médias dos teores séricos de albumina encontraram-se dentro dos níveis de referência. $2,7,16,18,19,20$ Nota-se que os maiores valores séricos dessa proteína encontram-se nos animais mais jovens, em fase de crescimento, com maior demanda metabólica, caracterizando a influência do fator etário sobre este parâmetro. Os valores apresentados em relação à avaliação da atividade sérica de aspartato-aminotransferase revelaram-se semelhantes aos valores de referência. ${ }^{2,6,7,9,10,12,13}$ Observa-se que as fêmeas apresentam maior atividade desta enzima que os animais do sexo masculino. Esse achado é explicado pela presença de animais lactantes no grupo de fêmeas, estado fisiológico que condiz com maior atividade sérica de AST, em função do aumento de massa hepática ocorrido nessa fase. ${ }^{15} \mathrm{O}$ fator etário também influencia a atividade sérica desta enzima. Os animais mais jovens apresentam menores valores, como referido também para a espécie bovina ${ }^{5}$, novamente se especula a possibilidade da presença de animais em lactação nos grupos 2 e 3, que 
apresentaram maior atividade sérica de AST. Os valores encontrados para a atividade sérica da gama-glutamiltransferase encontrada está de acordo com os níveis de referência para a espécie ovina. . $7,8,11,12,13,16 \mathrm{De}$ acordo com Gregory ${ }^{5}$, em bezerros lactentes a atividade sérica de GGT permanece elevada até os 3 meses de idade em função da ingestão de colostro. Este trabalho não pode confirmar essa tendência na espécie ovina, pois o grupo 1, que compreendia animais lactentes, também abrangia cordeiros desmamados.

\section{Conclusão}

Os valores de referência firmados neste trabalho, para ovinos da raça Santa Inês criados em regimes de semiconfinamento na região de Piedade no Estado de São Paulo, estiveram em conformidade com os resultados estabelecidos para referência, nesta espécie em animais criados em outras regiões e submetidos a formas variadas de manejo. O fator sexual mostrou exercer influência sobre a atividade sérica de AST, porém é possível que este fenômeno ocorra em conseqüência de variações do estado fisiológico das fêmeas. Os valores relacionados à concentração sérica de proteínas totais, à concentração sérica da fração albumina e à atividade sérica de AST demonstraram sofrer influência do fator etário. Estas conclusões ressaltam a importância de que estudos que avaliem a influência do estado fisiológico sobre os parâmetros avaliados nesse trabalho sejam realizados.

\section{Agradecimentos}

Ao CNPq (Conselho Nacional de Desenvolvimento Científico e Tecnológico).

\title{
Influence of age and sex on total serum protein and albumin and aspartato- aminotransferase and gama-glutamiltransferase serum activities on Santa Inês sheep
}

\begin{abstract}
This work establishes reference values for serum protein and albumin and serum activities of AST and GGT of Santa Inês sheep and evaluates the sexual and age influence on these values. Blood samples were collected from 161 clinically healthy sheep. The results allowed to establish the following reference values 5,86 + 0,96 g/dL (P>0,05) for serum protein, 2,33+0,43 $\mathrm{g} / \mathrm{dL}(\mathrm{P}>0,05)$ for albumin, 63,25+27,52 U/L (P>0,05) for AST and 28,45+14,53 U/L (P>0,05) for GGT. The result's analysis also allowed concluding that age and sex influence on albumin serum concentrations and AST serum activity and that GGT serum activity suffer age influence.
\end{abstract}

Key words: Biochemistry.

\section{Referências}

1 ROSENBERGER, G. Exame clínico dos bovinos. 2. ed. Rio de Janeiro: Guanbara, 1983, 429 p.

2 CARROLL, E. J.; KANEKO, J. J. The clinical significance of serum protein fractionation by electrophoresis. The California Veterinarian, v. 21, n. 1, p. 22-35, 1967.

3 BRAUN, J. P.; RICO, A. G.; BERNARD, P.; THOUVENOT, J. P.; BONNEFIS, M. J. Blood and tissue distribuition of gama glutamyl transferase in calves. Journal of Dairy Science, v. 61, n. 5, p. 596-599, 1977.
4 BRAUN, J. P.; BERNARD, P.; BURGAT, V.; RICO, A. G. Gamma glutamyl transferase in domestic animals. Veterinary Research Communications, v. 6, n. 2, p. $77-$ 90, 1983.

5 GREGORY, L. Valores padrões de referência de parâmetros bioquímicos séricos utilizados na avaliação das funções hepática e renal de bovinos da raça Jersey, criados no Estado de São Paulo. Influência de fatores etários, sexuais e da Infecção pelo Vírus da Leucose dos Bovinos. 1995, 161 f. Dissertação (Mestrado) Faculdade de Medicina Veterinária e Zootecnia, Universidade de São Paulo, São Paulo, 1995. 
6 YOUNG, J. E.; YOUNGER, R. L.; RADELEFF, D.; HUNT, L. M.; MACLARAN, J. K. Some observations on certain serum enzymes of sheep. American Journal of Veterinary Research, v. 26, n. 112, p. 641-643, 1965.

7 WEAVER, A. D. Haematological and plasma biochemical parameters in adult male sheep. Zentralblatt für Veterinärmedizin. Reibe $A, v .21, n$. 21, p. 1-7, 1974.

8 MARQUEZ, A. G.; FRATTINI, J. F.; GRIMOLDI, R. J.; FERNANDEZ, G.; TAMMES, F. A., WILLIANS, M. B. Perfil ezimatico em sueros de ruminantes: lático dehidrogenasa; gamma glutamil transpeptidasa; aldolasa; leucin amonopeptidasa colinesterasa. Gaceta Veterinaria, v. 39, p. 35-42, 1977.

9 HEALY, P. J.; FALK, R. H. Values of some biochemical constituents of the serum of clinically-normal sheep. Australian Veterinary Journal, v. 50, n. 7, p. 302-305, 1974.

10 GARDNER, D. E. Values for cetain some blood and urine constituents of normal young lambs. New Zealand Veterinary Journal, v. 21, n. 4, p. 70-73, 1973.

11 FORD, E. J. H. Activity of gamma-glutamyl transpeptidase and others enzymes in the serum of sheep with liver or kidney damage. Journal of Comparative Pathology, v. 84, n. 2, p. 231-243, 1974.

12 BOSS, P. H.; GERBER, H.; TSCHUDI, P. Haematologische und klinish-chemische untersuchungen bei schweizer schafrassen . Arch. Tierarztliche, v. 121, n. 2, p. 57-71, 1979.

13 GOHARY, G. S.; BICKHARDT, K. Der einflub des blutentnahmestresses auf blutmebwerte des schafes. Deutsche Tierärztliche Wochenschrift, n. 86, p. 225228, 1979.

14 SYKES, A. R.; COOP, R. L.; ROBINSON, M. G. Chronic subclinical ovine faciolosis: plasma glutamate dehydrogenase, gamaglutamil transpeptidase and aspartate aminotransferase and their significance as diagnostic aids. Research in Veterinary Science, v. 28, n. 1, p. 71-75, 1980.

15 RAMOS, J. J.; VERDE, M. T.; MARCA M. C.;
FERMINDEZ, A. Clincal chemical values and variations in Rasa Aragonesa ewes and lambs. Small Ruminants Research, v. 13, p. 133-139, 1993.

16 BAUMGARTNER, W.; PERTHANER, A. Influence of age, season, and pregnancy upon blood parameters in Austrian Karakul sheep. Small Ruminants Research, v. 13, n. 2, p. 147-151, 1993.

17 DIAS, M. I. R.; CARNEIRO, M. J.; AZEVEDO, J. T.; FERREIRA, A. J.; CABRITA, A. M. S. Parâmetros hematológicos, de bioquímica sanguínea geral, electrólitos plasmáticos e das hormonas relacionadas com a função da tireóide na ovelha da raça Churra da Terra Quente. Revista Portuguesa de Ciências Veterinárias, v. 99, n. 550, p. 99-107, 2004.

18 RIBEIRO, L. A. O.; MATTOS, R. C.; GONZALES, F. H. D.; WALD, V. B.; SILVA, M. A.; LA ROSA, V. L. Perfil metabólico de ovelhas Border Leicester $\mathrm{x}$ Texel durante a gestação e a lactação. Revista Portuguesa de Ciências Veterinárias, v. 99, n. 551, p. 155-159, 2004.

19 BRITO, M. A.; GONZALES, F. D.; RIBEIRO, L. A. O.; CAMPOS, R.; LACERDA, L.; BARBOSA, P. R.; BERGMAN, G. Composição do sangue e do leite em ovinos leiteiros do sul do Brasil: variações na gestação e lactação. Ciência Rural, v. 36, n. 3, p. 942-948, 2006.

20 BALIKCI, E.; YILDIZ, A.; GÜRDOGAN, F. Blood metabolite concentrations during pregnancy and postpartum in Akkaraman ewes. Small Ruminants Research, v. 67, n. 2/3, p. 247-251, 2007.

21 GORNALL, A. G.; BARDAWILL, C. J.; DAVID, M. $M$. Determination of serum proteins by means of biuret reaction. Journal of Biological Chemistry, v. 177, n. 2, p. 751-766, 1949.

22 STRUFALDI, B. Prática de bioquímica clínica. São Paulo. Faculdade de Ciências Farmacêuticas da Universidade de São Paulo, 1987. 399 p.

23 DOUMAS, I. B. T.; BIGGES, H. G. Standard methods of clinical chemistry. 7. ed. London: Academic Press, 1972. $13 \mathrm{p}$.

24 BERQUÓ, E. S.; SOUZA, J. M. P.; GOTLIEB, S. L. D. Bioestatística. São Paulo: Pedagógica e Universitária, 1981. 350 p. 